\title{
Pyomelanin Production From a Marine Isolate of Acinetobacter Spp.
}

\author{
Jean Loi ${ }^{1}$, Tan Shi Yi ${ }^{1}$, Attapol Pinsa ${ }^{1}$, Sakinah Mulyana', \\ Lloyd George Singaretnam ${ }^{2}$, Meliana Riwanto ${ }^{1}$ and Jason Chang ${ }^{1}$ *
}

${ }^{1}$ School of Applied Science, Temasek Polytechnic, 21 Tampines Avenue 1, Singapore 529757

${ }^{2}$ Present address: School of Applied Science, Republic Polytechnic, 9 Woodlands Avenue 9, Singapore 738964

*Corresponding author

\section{Keywords}

Bacterial pigments, Acinetobacter spp., Pyomelanin production, $\mathrm{pH}$

\section{Article Info}

Accepted:

18 May 2020

Available Online:

10 June 2020

\begin{abstract}
A B S T R A C T
There is growing interest in the use of natural pigments for a wide range of applications. A search for pigment-producing bacteria led to the isolation of a marine bacterium that produced a diffusible brown pigment. The bacterium was identified as Acinetobacter spp.from 16S rRNA gene sequencing. The pigment displayed free-radical scavenging activity and was characterized as a melanin through solubility tests, UV-Vis spectrophotometry and Fourier transform infrared (FTIR) spectroscopy. Melanin production was blocked by sulcotrione, an inhibitor of 4hydroxyphenylpyruvate dioxygenase (HPPD), the enzyme responsible for producing homogentisic acid (HGA), which is the monomeric precursor of pyomelanin. Inactivation of melanin synthesis by HPPD inhibition confirmed that the pigment was pyomelanin. Acinetobacter spp. required at least 12 days to produce approximately $1 \mathrm{~g} / \mathrm{L}$ of pyomelanin when it was grown in basal medium supplemented with L-tyrosine. The rate of pyomelanin production was not influenced by nutrient levels in growth media. Supplementation with different carbon sources and the use of nutrient-rich media had no effect in accelerating pigment production. However, $\mathrm{pH}$ had a major effect on pyomelanin formation by significantly reducing the time taken to produce the pigment. When the $\mathrm{pH}$ of growth medium ( $\mathrm{pH} 5.5$ ) was adjusted to $\mathrm{pH} 8$, bacteria were able to produce pyomelanin in 7 days instead of 12-14 days.
\end{abstract}

\section{Introduction}

The global shift away from manufacturing synthetic and convenient products to natural and sustainable products has been accelerating over recent years. An emerging area is the use of biological pigments as alternatives to synthetic ones (Venil et al., 2013). Pigments are essential colorants in many industries including food and beverage, paint, plastics, cosmetics, clothing, printing and many others. The list of reasons for discontinuing the use of synthetic pigments is growing and includes its potential toxicity to plant, animal and human populations, widespread environmental contamination and negative impact on ecosystems (Chung, 2016; Lellis et al., 2019; Tkaczyk et al., 2020).

Natural pigments are less harmful alternatives and they possess additional useful characteristics such as antioxidant, anti-UV 
(ultraviolet), antimicrobial, anti-fungal and anti-tumour activities that have not been fully exploited (Venil et al., 2013). Natural pigments are widespread and can be found in plants, animals, fungi and bacteria but bacterial pigments may be the most attractive in terms of production on a commercial scale. Although plant pigments are the most widely used of the biological pigments with a wide range of applications (Mansour, 2018), producing pigments from bacteria has several advantages. The rapid life cycle of bacteria allows for easy and frequent pigment extractions, the cultivation of bacteria can be readily scaled up in a controlled environment that is free from seasonal and climatic variations, pests and disease. Moreover, bacteria are readily amendable for strain improvement via genetic manipulation (Malik et al., 2012).Hence, there has been growing interest in the application of bacterial pigments as therapeutic and medicinal agents, non-toxic inks for printing, dyes for food and textiles and colorants for cosmetics (Venil et al., 2013).

We report here the isolation, culture and identification of a marine isolate of Acinetobacter spp. recovered from seawater off Singapore. The bacterium produced a diffusible dark-brown pigment, subsequently identified as pyomelanin. Pyomelanin is one of several types of melanins, whichare heterogenous polymers of phenolic or indolic compounds produced by a wide variety of prokaryotes and eukaryotes (Nosanchuk and Casadevall, 2003; Plonka and Grabacka, 2006). Melanins have several properties in common, including the ability to absorb ultraviolet (UV) light, ability to scavenge free radicals, inability to dissolve in aqueous or organic fluids, resistance to concentrated acid and susceptibility to bleaching by oxidizing agents (Bustamante et al., 1993; Nosanchuk and Casadevall, 2003). Pyomelanin is a darkbrown pigment formed from the accumulation of homogentisic acid (HGA), an intermediate molecule in the degradation of phenylalanine and tyrosine. HGA can autooxidise and selfpolymerise into pyomelanin, a molecular structure of unknown organization and size (Turick et al., 2010). This study provides a description of the production, characterization and subsequent identification of pyomelanin from an isolate of Acinetobacter spp.and the effect of $\mathrm{pH}$ on pyomelanin production.

\section{Materials and Methods}

\section{Isolation and culture of bacteria}

Pigment-producing bacteria were isolated from seawater off the North-East coast of Singapore with basal agar medium containing $0.5 \%$ (w/v) L-tyrosine. Agar plates were incubated at $30^{\circ} \mathrm{Caerobicallyfor} 48 \mathrm{~h}$ and examined for pigment-producing colonies. A pigment-producing colony, named PRSW10118-BK (BK), was selected for further study. Thereafter, bacteria were cultivated on either nutrient agar/broth or basal medium with $0.5 \%$ L-tyrosine and grown at $35^{\circ} \mathrm{Caerobically.} \mathrm{Basal} \mathrm{media}$ containing $0.5 \%$ L-tyrosine was prepared according to Yabuuchi and Ohyama (1972). Agar Bacteriological (1.5\% w/v) (Oxoid, UK) was added to the liquid medium to make basal agar medium. Nutrient broth (Oxoid, UK) was prepared according to the manufacturer's instructions, with $0.5 \%$ L-tyrosine. All media were sterilized by autoclaving at $121^{\circ} \mathrm{C}$ for $20 \mathrm{~min}$ before use.

\section{DNA extraction and 16S rRNA gene sequencing}

Bacterial DNA was extracted using the Wizard® Genomic DNA Purification Kit (Promega, USA) as described in the manufacturer's instructions. The $16 \mathrm{~S}$ rRNA gene was amplified and sequenced using bacterial universal primers $27 \mathrm{~F}$ (5'- 
AGAGTTTGATCCTGGCTCAG-3') and 1492R (5'-GGTTACCTTGTTACGACTT$\left.3^{\prime}\right)$. PCR was carried out in $25 \mu \mathrm{L}$ volumes consisting of genomic DNA (50 ng), $1 \mu \mathrm{L}$ forward primer $(12.5 \mu \mathrm{M}), 1 \mu \mathrm{L}$ reverse primer $(12.5 \mu \mathrm{M}), 12.5 \mu \mathrm{L} 2 \times$ Phusion HighFidelity PCR Master Mix (Thermo Scientific) and adjusted to $25 \mu \mathrm{L}$ with nuclease-free water. PCR was performed in an $\mathrm{ABI} /$ Perkin Elmer 9600 PCR machine with the following cycling conditions: initial denaturation at $95^{\circ} \mathrm{C}$ for $5 \mathrm{~min}, 35$ cycles of denaturation at $95^{\circ} \mathrm{C}$ for $30 \mathrm{~s}$, annealing at $50^{\circ} \mathrm{C}$ for $1 \mathrm{~min}$ and extension at $72^{\circ} \mathrm{C}$ for $2 \mathrm{~min}$.

A final extension was performed at $72^{\circ} \mathrm{C}$ for 10 min. PCR products were visualized in a $1 \%$ agarose gel, stained with Sybr Green and purified using the Wizard® SV Gel and PCR Clean-Up System (Promega, USA). Sanger sequencing was performed by Bio Basic Asia Pacific Pte Ltd(Singapore). DNA sequences were then analyzed using BLAST available from the National Center of Biotechnology Information (NCBI) website.

\section{Production and extraction of bacterial melanin}

To facilitate melanin recovery and minimize contamination of the final melanin product, basal and not nutrient-rich media, supplemented with $0.5 \%$ L-tyrosine, was used to grow the bacteria. Inoculated flasks were placed in a shaking incubator $(150 \mathrm{rpm})$ at $35^{\circ} \mathrm{C}$ until the medium turned dark-brown (at least 12 days). Cultures were then centrifuged at $7000 \times \mathrm{g}($ Beckman, JAL-16500) for 30 min. The supernatant was recovered and the $\mathrm{pH}$ was adjusted to $\mathrm{pH} 2$ with $6 \mathrm{M} \mathrm{HCl}$ and left to stand for at least $2 \mathrm{~h}$. The precipitate was then thoroughly washed three times with generous volumes $(220 \mathrm{~mL})$ of sterile MilliQ water. Centrifugation was carried out at 7000 $\times \mathrm{g}$ for $10 \mathrm{~min}$ each wash. The purified pigment was then dried in a $60^{\circ} \mathrm{C}$ oven overnight and weighed. To assess whether bacterial growth and pigment synthesis could be accelerated, the basal medium was supplemented with different carbon sources. Basal medium containing $0.5 \%$ L-tyrosine was supplemented with $1 \%$ of the following: glucose, sucrose, mannose, glycerol, Dsorbitol, fructose or maltose in separate flasks. The $\mathrm{pH}$ of basal medium was adjusted from $\mathrm{pH} 5.5$ to $\mathrm{pH} 6,7$ or 8 to assess whether $\mathrm{pH}$ had any effect on the time required to synthesize the pigment.

\section{Solubility and oxidizability tests}

The ability of the pigment to dissolve in a variety of solvents and be bleached by hydrogen peroxide was assessed using the methods described by Guo et al., (2014). Solvents included100\% methanol, $100 \%$ ethanol, 99\% acetone, phenol, chloroform, sodium hydroxide (1M) and dimethyl sulfoxide (DMSO).To determine whether the pigment could be oxidized by hydrogen peroxide, a $0.01 \%$ melanin solution was mixed with $\mathrm{H}_{2} \mathrm{O}_{2}$ at different final concentrations (1,2 and 5\%). Absorbance was measured using a Shimadzu, UV-1800 spectrophotometer.

\section{$\mathrm{UV}-\mathrm{V}$ is spectroscopy}

A $0.005 \%(\mathrm{w} / \mathrm{v})$ solution of bacterial melanin was made by dissolving extracted pigment in $0.1 \mathrm{M} \mathrm{NaOH}$. The melanin solution was subjected to a spectral scan using a Shimadzu, UV-1800 spectrophotometer at $200-800 \mathrm{~nm}$ to determine peak absorbance. Synthetic melanin (Merck, USA) was prepared and analysed in the same manner.

\section{FTIR spectroscopy}

Fourier transform infrared (FTIR) spectroscopy was used to analyse the bacterial melanin against eumelan in from cuttlefish 
(Sepia officinalis). Melanin was ground with infrared quality dry $\mathrm{KBr}$ and pressed into a pellet with an MHP-1 Pelletizer. The infrared (IR) spectrum (4000-400 $\mathrm{cm}^{-1}$ ) was recorded with a Shimadzu IR Prestige-21 NIR system and AIM 8800 IR microscope.

\section{Free-radical scavenging assay}

A $0.004 \%$ (w/v) DPPH (2,2-diphenyl-1picrylhydrazyl) solution was prepared by dissolving DPPH powder in absolute methanol. The test samples, at concentrations of $20,40,60,80,100,120,140 \mu \mathrm{g} / \mathrm{mLwere}$ prepared by dissolving dried pigment in $10 \mathrm{mM}$ Tris-HCl (pH 8). One hundred microliters of sample was mixed with $100 \square \mathrm{L}$ of DPPH solution in a 96-well flat bottom microtitre plate (Greiner Bio-One, Germany). Absorbance was measured at 520nm after the mixture was left at room temperature in the dark for $30 \mathrm{~min}$. Ascorbic acid was used as the positive control. The strength of scavenging activity was expressed as follows:

Scavenging activity $(\%)=$ Absorbance of control - Absorbance of test sample/ (Absorbance of control) $\times 100$

\section{Specific inhibitors of melanin synthesis}

Sulcotrione and kojic acid, known inhibitors of 4-Hydroxyphenylpyruvate dioxygenase (HPPD) and tyrosinase/laccase, respectively, were used to determine the identity of the bacterial melanin. Sulcotrione was added to tyrosine-supplemented basal agar medium at final concentrations of 10,20 and $50 \mu \mathrm{M}$.

Kojic acid was added to tyrosinesupplemented basal agar plates at final concentrations of $50 \mu \mathrm{M}, 100 \mu \mathrm{M}$ and 200 $\mu \mathrm{M}$. Plates were streaked with the bacterial isolate $\mathrm{BK}$ and incubated aerobically at $35^{\circ} \mathrm{C}$ and visually inspected after $48 \mathrm{~h}$.

\section{Results and Discussion}

\section{Identification of the pigment-producing bacterium}

The pigment-producing bacterium isolated from seawater off Singapore was identified as Acinetobacter spp. through $16 \mathrm{~S}$ rRNA gene sequencing. Electropherograms of the forward and reverse sequences were checked and verified using Chromas 2.6.6. Both forward and reverse sequences were aligned with sequences in GenBank by the BLAST algorithm, which matched the sequences to Acinetobacter venetianus (95\% identity). We have therefore classified bacterial isolate $\mathrm{BK}$ as Acinetobacter spp.

\section{Characterization and identification of the bacterial pigment}

Acinetobacter spp. isolate BK produced an extracellular diffusible pigment, which could be precipitated and extracted from an acidified solution (Fig. 1). After 12-14 days of growth, on average, the yield of bacterial pigment was approximately $1 \mathrm{~g} / \mathrm{L}$ in basal medium containing L-tyrosine. The extracellular pigment was identified as a melanin from its solubility profile, UV-Vis absorption spectrum and FTIR spectroscopy. The pigment was insoluble in water and a number of solvents but could be dissolved in alkali solution. It was soluble in dimethylsulfoxide (DMSO) and partially soluble in methanol (Table 1). Moreover, it could be decolourized with $\mathrm{H}_{2} \mathrm{O}_{2}$, which is consistent with other bacterial melanins described previously (Chen et al., 2004; Sajjan et al., 2010; Guo et al., 2014).Bacterial melanin from Acinetobacter spp. BK strongly absorbed light in the UV region, peaking at $215 \mathrm{~nm}$. Synthetic melanin produced an identical peak in the same region (Fig. 2). The spectral scan of the pigment from Acinetobacter spp. BK is typical of most 
melanins, showing a strong optical absorbance in the UV region that decreased towards longer wavelengths. Peak absorption of most melanins ranges between 196-300 $\mathrm{nm}$, depending on the melanin source (Pralea et al., 2019). Melanin is well known for possessing antioxidant activity (Bustamante et al., 1993; Jacobson et al., 1995). To assess whether the pigment displayed antioxidant activity, it was subjected to a free-radical scavenging assay using the stable free radical DPPH. Absorbance of the purple solution of DPPH decreased as it turned pale yellow as a result of losing electrons scavenged by the pigment. As the concentration of melanin increased, its free-radical scavenging activity also increased and then plateaued at concentrations $\geq 100 \square \mathrm{g} / \mathrm{mL}$, as did ascorbic acid (Fig. 3). Although not as strong an antioxidant as ascorbic acid, the pigment from Acinetobacter spp. BK clearly displayed free radical scavenging activity.

FTIR spectroscopy was used to determine the functional groups and fingerprint regions in the melanin (Fig. 4). Both the bacterial melanin and eumelanin displayed peaks that were reflective of structures expected to be found in melanin. Firstly, both pigments displayed similar peaks in the functional group region with broad peaks at 3294.42 and $3387.00 \mathrm{~cm}^{-1}$, respectively, which is characteristic of $\mathrm{O}-\mathrm{H}$ stretching (Coates, 2000). For the bacterial melanin, the peaks at the following wave numbers and their corresponding structures were: 2931.80 aliphatic $\mathrm{C}-\mathrm{H}$ stretching; 1651.07 aromatic $\mathrm{C}=\mathrm{C}$ conjugated with $\mathrm{C}=\mathrm{O}$ and/or $\mathrm{COO}^{-}$ groups; 1535.34aromatic $\mathrm{C}=\mathrm{C}$ bonds; 1450.47 aliphatic $\mathrm{C}-\mathrm{H} ; \quad 1226.73$ phenol $\mathrm{C}-\mathrm{O}$ stretching; 1056.99 primary alcohol C-O stretching (Coates, 2000; Turick et al., 2002; Singh et al., 2018). For cuttlefish eumelanin, the peak at 1597.00 could be attributed to carbonyl stretching in indole quinone; $1355.60 \mathrm{~cm}^{-1}$ could be from bending $\mathrm{O}-\mathrm{H}$ and
$\mathrm{NH}$ bonds combined with various modes of aromatic rings(Glass et al., 2012).Although production of eumelanin has been described in bacteria (Plonka and Grabacka, 2006), the clear difference between Acinetobacter melanin and eumelanin inthe fingerprint region, at and below $1651.07 \mathrm{~cm}^{-1}$, strongly suggested that the Acinetobacter melanin could not be eumelanin.

This was further supported by results from inhibition tests with kojic acid, a chelator of copper ions and inhibitor of coppercontaining enzymes like tyrosinase and laccase, which failed to block melanin production by Acinetobacter spp. isolate BK. Tyrosinase is an enzyme involved in the biosynthesis of eumelanin (Plonka and Grabacka, 2006). However, when sulcotrione, a specific inhibitor of HPPD, was added to growth media, it was able to completely inhibit melanin synthesis (Fig. 5). HPPD is the enzyme responsible for converting 4hydroxyphenylpyruvic acid into HGA, the monomeric precursor of pyomelanin (Turick et al., 2010). This was conclusive evidence that the pigment produced by Acinetobacter spp. BK was indeed pyomelanin.

Pyomelanin is formed from HGA, which is produced from the degradation of phenylalanine and tyrosine. Tyrosine is converted to 4-hydroxyphenylpyruvic acid then HGA, which is excreted from bacterial cells where it autoxidizes into benzoquinoneacetic acid and self-polymerises into pyomelanin (Turick et al., 2010). Acinetobacter spp. BK required 12-14 days to turn the basal medium, with an initial $\mathrm{pH}$ of 5.5 , completely dark brown. The $\mathrm{pH}$ of the growth medium at day 12 was found to range from $\mathrm{pH} 8.1$ to 8.7. The addition of glucose, sucrose, mannose, glycerol, D-sorbitol, fructose and maltose as the sole carbon source to the basal medium, did not accelerate the formation of pyomelanin (data no shown). 
Table.1 Solubility and oxidizability of melanin from Acinetobacter spp. BK

\begin{tabular}{|l|l|l|}
\hline \multicolumn{1}{|c|}{ Test } & \multicolumn{1}{c|}{ Treatment } & Result \\
\hline Solubility & $\mathrm{H}_{2} \mathrm{O}$ & Insoluble \\
\cline { 2 - 3 } & $\mathrm{HCl}(1 \mathrm{M})$ & Insoluble \\
\hline & Acetone & Insoluble \\
\hline & Chloroform & Insoluble \\
\hline & Ethanol & Insoluble \\
\cline { 2 - 3 } & Phenol & Insoluble \\
\hline & Methanol & Partially soluble \\
\cline { 2 - 3 } & Dimethylsulfoxide & Soluble \\
\cline { 2 - 3 } & $\mathrm{NaOH}(1 \mathrm{M})$ & Soluble \\
\hline \multirow{2}{*}{ Oxidizability } & $1 \%, 2 \%, 5 \% \mathrm{H}_{2} \mathrm{O}_{2}$ & Decolorized (dark to near colourless) \\
\hline
\end{tabular}

a

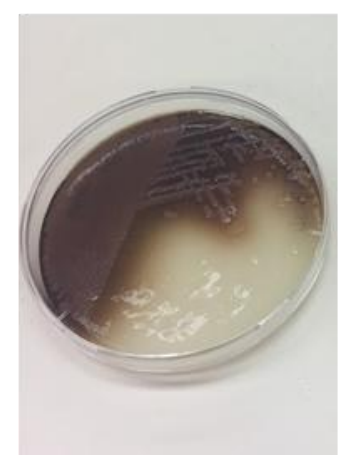

$\mathrm{b}$

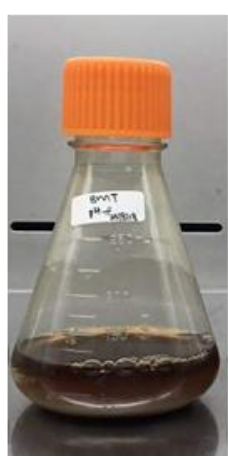

$\mathrm{c}$

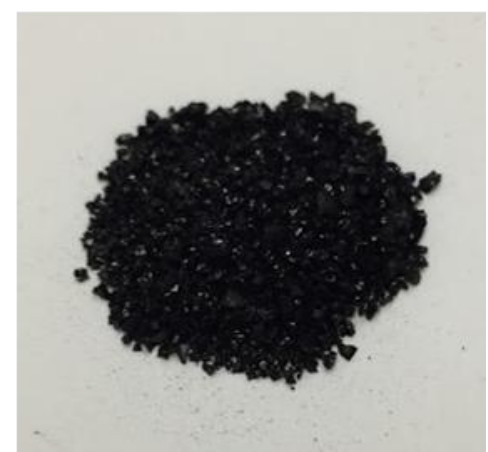

Fig.1 Acinetobacter spp. BK producing diffusible brown melanin on (a) agar and in (b) basal medium containing $0.5 \%$ (w/v) L-tyrosine. (c) The melanin was extracted by precipitation in acid and washed thoroughly with water

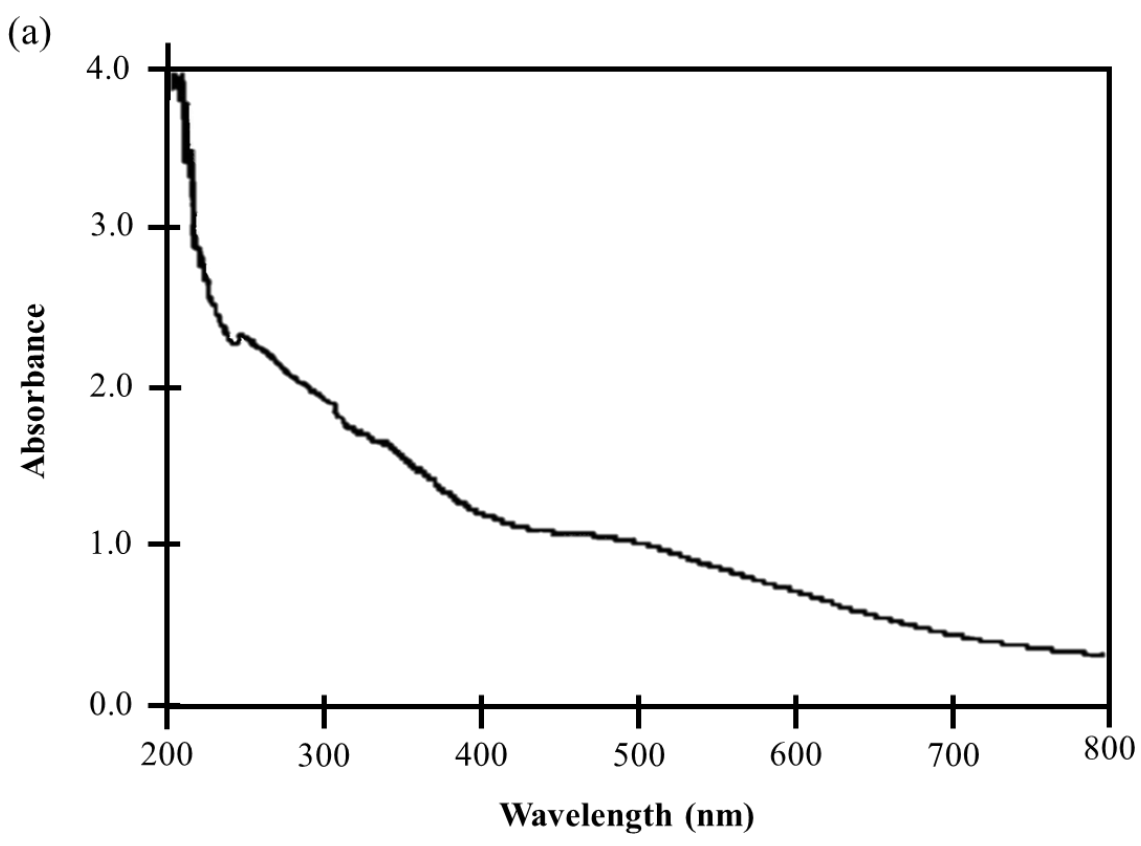




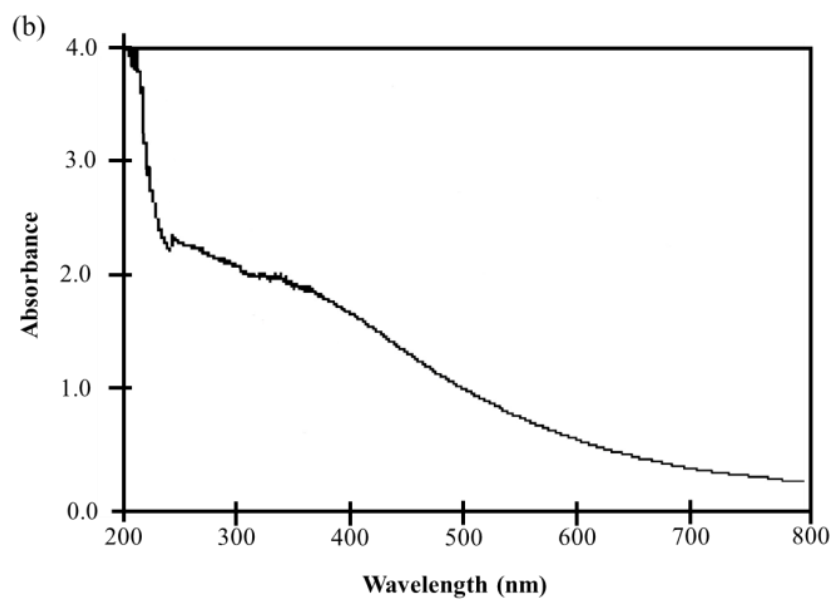

Fig.2 Absorption spectra of (a) melanin produced by bacterial isolate BK and (b) synthetic melanin. Peak absorption was in the UV region at $215 \mathrm{~nm}$ for both pigments

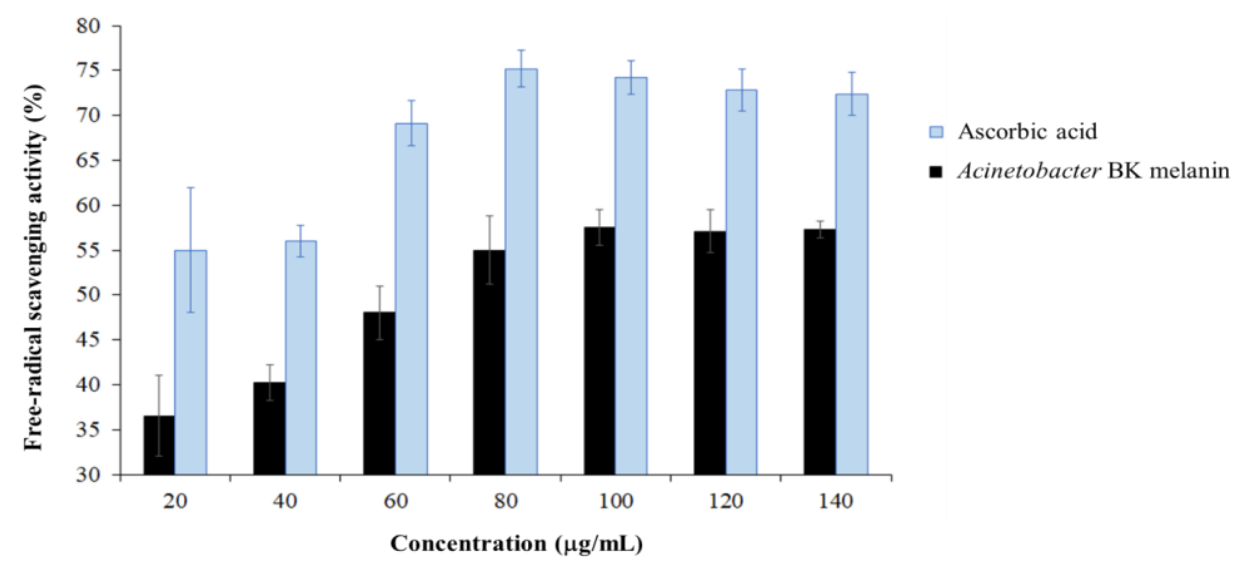

Fig.3 DPPH scavenging activity of melanin from Acinetobacter spp. isolate BK compared to ascorbic acid, a known antioxidant

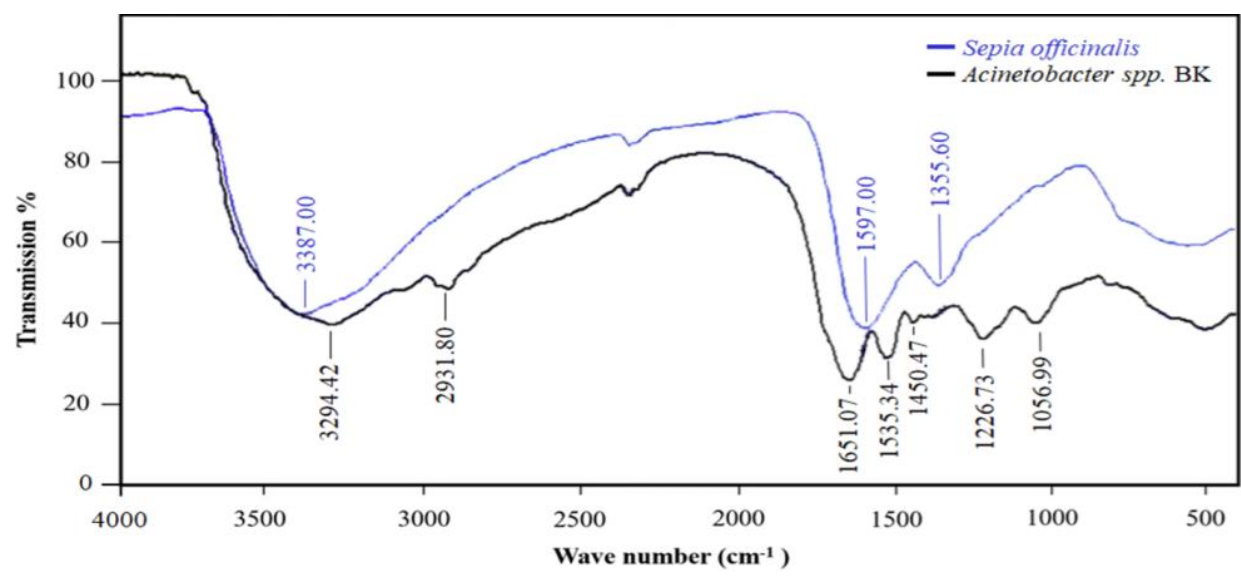

Fig.4 Fourier transform infrared scans of melanin isolated from Acinetobacter spp. isolate BK and eumelanin from Sepia officinalis (cuttle fish). The pigments showed some similarity in the functional group region but differed significantly in the fingerprint region, encompassing peaks with wave numbers $\leq 1651.07 \mathrm{~cm}^{-1}$ 


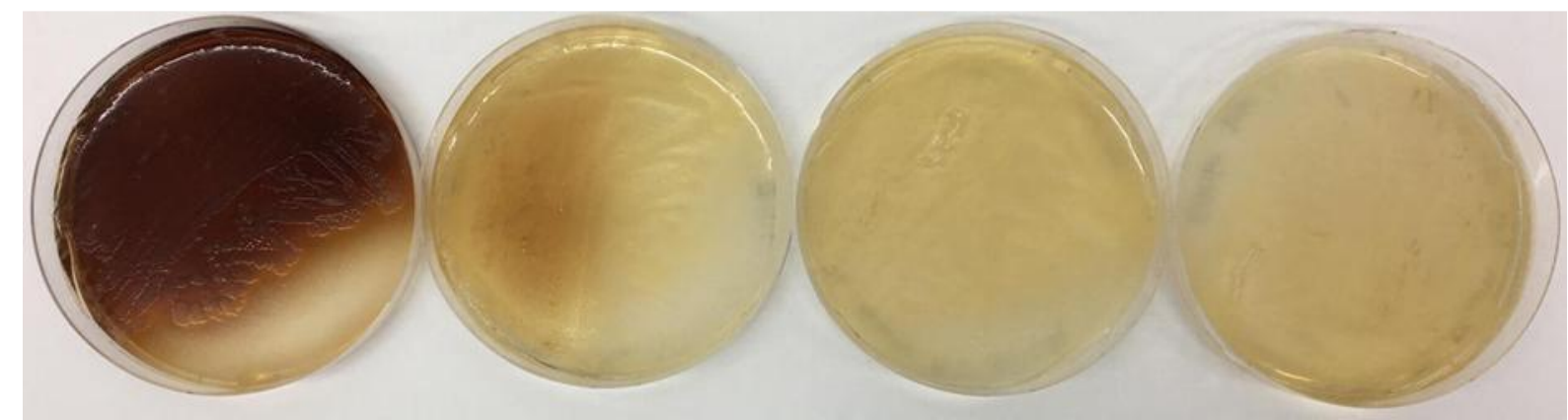

Fig.5 Acinetobacter spp. BK grown on basal agar supplemented with $0.5 \%$ L-tyrosine, containing sulcotrione at (a) $0 \mathrm{mM}$ (b) $10 \mathrm{mM}$ (c) $20 \mathrm{mM}$ and (d) $50 \mathrm{mM}$. Melanin synthesis was partially inhibited at $10 \mathrm{mM}$ but was completely inhibited at concentrations $\geq 20 \mathrm{mM}$

Moreover, nutrient-rich broth ( $\mathrm{pH}$ 7) containing L-tyrosine, which should have accelerated growth of the bacterium also took at least 12 days for the broth to turn dark brown. The level of nutrients in the media had no effect on the time taken to produce pyomelanin. However, pigment formation could be accelerated when the starting $\mathrm{pH}$ of the basal medium was increased from $\mathrm{pH} 5.5$ to 8 , which reduced the production time from 12-14 to 7 days. There was no difference between media at $\mathrm{pH} 5.5$ and $\mathrm{pH} 6$ and only a slight reduction to 11-12 days at $\mathrm{pH} 7$ (data not shown). Lagunas-Muñoz et al., (2006) described a similar positive effect of alkaline $\mathrm{pH}$ on eumelanin synthesis in recombinant $E$. coli cells, where a slightly alkaline $\mathrm{pH}$ promoted autooxidation and polymerization of eumelanin. They found that at $\mathrm{pH} 7$ there was adrastic decrease in eumelanin production after $12-18 \mathrm{~h}$ of the initial production stage but the rate of eumelanin formation was maximal at $\mathrm{pH} 7.5-8$ (Lagunas-Muñoz et al., 2006).

Visible pyomelanin took longer to form in liquid basal medium ( $\mathrm{pH}$ 5.5; at least 12 days) compared to solid agar medium (2 days). The initial acidic $\mathrm{pH}$ of the liquid basal medium probably contributed to the extended time required for pyomelanin production because acidic conditions are unfavourable to melanogenesis and may even inhibit melanin synthesis if the $\mathrm{pH} \leq 5.5$ (Ancans et al., 2001). It may have taken well over a week for Acinetobacter spp. to secrete enough metabolites into the growth medium to raise the $\mathrm{pH}$ to a level that is conducive for melanin formation. Another limiting factor may be the amount of HGA present in the medium for melanin polymerization to occur. In broth, due to the larger volume compared to agar plates, it takes much longer to accumulate enough monomeric HGA to polymerize into pyomelanin. HGA is only excreted out of the bacterial cell when its production exceeds that of HGA-oxidase activity (Turick et al., 2010). If HGA production does not exceed HGAoxidase activity then HGA is converted to 4maleyacetoacetic acid and no pyomelanin is formed. Therefore, it may require many days for significant amounts of HGA to accumulate in the medium such that it is sufficient for assembly of macromolecular pyomelanin.

Bacteria are increasingly used as biofactories to produce biological products. Natural pigments like pyomelanin could easily be produced and extracted from bacteria. However, to optimize pigment production it is important to understand the environmental conditions that favour pigment formation as well as the biochemical pathway leading to its synthesis. 
The present study demonstrated the effect of alkaline $\mathrm{pH}$ in reducing the time it takes to produce pyomelanin. To successfully produce the pigment on commercial scale it may be necessary to also consider overcoming the limiting amounts of excreted HGA. This could be done by employing genetic mutants with a modified biochemical pathway that is directed at overproducing HGA.

\section{Acknowledgement}

This study was supported by the Temasek Polytechnic Research Fund. The authors would like to thank the Research and Technology Development department at Temasek Polytechnic for their financial support.

\section{References}

Ancans J., D. J. Tobin, M. J. Hoogduijn, N. P. Smit, K. Wakamatsu and Thody, A. J. 2001. Melanosomal pH controls rate of melanogenesis, eumelanin/ phaeomelanin ratio and melanosome maturation in melanocytes and melanoma cells. Exp Cell Res. 268: 2635.

Bustamante, J., L. Bredeston, G. Malanga and Mordoh, J. 1993. Role of melanin as a scavenger of active oxygen species. Pigment Cell Res. 6: 348-353.

Coates, J. 2000. Interpretation of infrared spectra, a practical approach In: Meyers, R. A. (Ed.), Encyclopedia of analytical chemistry. John Wiley \& Sons, Chichester. 10815-10837.

Chen, Y., Y. Deng, J. Wang, J. Cai and Ren, G. 2004.Characterization of melanin produced by a wild-type strain of Bacillus thuringiensis. J Gen Appl Microbiol. 50:183-188.

Chung, K. T. 2016. Azo dyes and human health: A review.J Environ Sci Health C Environ Carcinog Ecotoxicol Rev.
34:233-261.

Glass, K., S. Ito, P. R. Wilby, T. Sota, A. Nakamura, C. R. Bowers, J. Vinther, S. Dutta, R. Summons, D. E. Briggs, K. Wakamatsu and Simon, J. D. 2012. Direct chemical evidence for eumelanin pigment from the Jurassic period. Proc Natl Acad Sci USA. 26:10218-10223.

Guo, J., Z. Rao, T. Yang, Z. Man, M. Xu and Zhang, X. 2014. High-level production of melanin by a novel isolate of Streptomyces kathirae. FEMS Microbiol Lett. 357: 85-9.

Jacobson, E. S., E. Hove and Emery, H. S. 1995. Antioxidant function of melanin in black fungi. Infect Immun. 63: 49444945.

Lagunas-Muñoz, V. H., N. CabreraValladares, F. Bolívar, G. Gosset and Martínez, A. 2006. Optimum melanin production using recombinant Escherichia coli. J Appl Microbiol. 101: 1002-1008.

Lellis, B., C. Z. Fávaro-Polonio, J. A. Pamphile and Polonio, J. C.2019.Effects of textile dyes on health and the environment and bioremediation potential of living organisms. Biotech Res and Innov. 3: 275-290.

Malik, K., J. Tokkas and Goyal, S. 2012. Microbial Pigments: A review. International J. Microbial Resource Technol. 1: 361-365.

Mansour, R. 2018. Natural Dyes and Pigments: Extraction and Applications In: Yusuf, M. (Ed.), Handbook of Renewable Materials for Coloration and Finishing. John Wiley \& Sons, Hoboken. 75-102.

Nosanchuk, J. D., and Casadevall, A. 2003. The contribution of melanin to microbial pathogenesis. Cell Microbiol. 5: 203-223.

Plonka, P. M., and Grabacka, M. 2006. Melanin synthesis in microorganismsbiotechnological and medical aspects. 
Acta Biochim Pol.53:429-443.

Pralea, I. E., R. C. Moldovan, A. M. Petrache, M. Ilies, S. C. Hegheș, I. Ielciu, R. Nicoara, M. Moldovan, M. Ene, M. Radu, A. Uifalean and Iuga, C. A. 2019. From Extraction to Advanced Analytical Methods: The Challenges of Melanin Analysis. Int J Mol Sci. 20: 3943.

Sajjan, S., G. Kulkarni, V. Yaligara, L. Kyoung and Karegoudar, T. B. 2010. Purification and physiochemical characterization of melanin pigment from Klebsiella $s p$. GSK.J Microbiol Biotechnol. 20:1513-1520.

Singh, D., J. Kumar and Kumar, A. 2018. Isolation of pyomelanin from bacteria and evidences showing its synthesis by 4-hydroxyphenylpyruvate dioxygenase enzyme encoded by $h p p D$ gene. Int $\mathbf{J}$ Biol Macromol. 119: 864-873.
Tkaczyk, A., K. Mitrowska and Posyniak, A. 2020. Synthetic organic dyes as contaminants of the aquatic environment and their implications for ecosystems: A review. Sci Total Environ. 717:137222.

Turick, C. E., L. S. Tisa and Caccavo, F. Jr. 2002.Melanin production and use as a soluble electron shuttle for Fe(III) oxide reduction and as a terminal electron acceptor by Shewanella algae BrY.Appl Environ Microbiol. 68:2436-2444.

Turick, C. E., A. S. Knox, J. M. Becnel, A. A. Ekechukwu and Milliken, C. E. 2010. Properties and Function of Pyomelanin In:Elnashar, M. (Ed.), Biopolymers. IntechOpen, London. 449-472.

Venil, C. K., Z. A. Zakaria and Ahmad, W. A. 2013. Bacterial pigments and their applications.Process Biochem. 48: 1065-1079.

\section{How to cite this article:}

Jean Loi, Tan Shi Yi, Attapol Pinsa, Sakinah Mulyana, Lloyd George Singaretnam, Meliana Riwanto and Jason Chang. 2020. Pyomelanin Production From a Marine Isolate of Acinetobacter Spp.. Int.J.Curr.Microbiol.App.Sci. 9(06): 2250-2259.

doi: https://doi.org/10.20546/ijcmas.2020.906.275 